\title{
Vasodilatation in the rat dorsal hindpaw induced by activation of sensory neurons is reduced by Paclitaxel
}

\author{
N.G. Gracias ${ }^{1}$, T.R. Cummins ${ }^{1,7}$, M.R. Kelley ${ }^{2,3,5}$, D.P. Basile ${ }^{4}$, T. Iqbal ${ }^{1}$, and M.R. \\ Vasko $1,6,8,9$ \\ ${ }^{1}$ Department of Pharmacology and Toxicology, Indiana University School of Medicine, \\ Indianapolis, IN 46202, USA \\ ${ }^{2}$ Department of Pediatrics (Section of Hematology/Oncology), Herman B Wells Center for \\ Pediatric Research, Indiana University School of Medicine, Indianapolis, IN 46202, USA \\ ${ }^{3}$ Department of Biochemistry and Molecular Biology, Indiana University School of Medicine, \\ Indianapolis, IN 46202, USA \\ ${ }^{4}$ Department of Cellular and Integrative Physiology, Indiana University School of Medicine, \\ Indianapolis, IN 46202, USA
}

\begin{abstract}
Peripheral neuropathy is a major side effect following treatment with the cancer chemotherapeutic drug paclitaxel. Whether paclitaxel-induced peripheral neuropathy is secondary to altered function of small diameter sensory neurons remains controversial. To ascertain whether the function of the small diameter sensory neurons was altered following systemic administration of paclitaxel, we injected male Sprague Dawley rats with $1 \mathrm{mg} / \mathrm{kg}$ paclitaxel every other day for a total of four doses and examined vasodilatation in the hindpaw at day 14 as an indirect measure of calcitonin gene related peptide (CGRP) release. In paclitaxel-treated rats, the vasodilatation induced by either intradermal injection of capsaicin into the hindpaw or electrical stimulation of the sciatic nerve was significantly attenuated in comparison to vehicle-injected animals. Paclitaxel treatment, however, did not affect direct vasodilatation induced by intradermal injection of methacholine or CGRP, demonstrating that the blood vessels' ability to dilate was intact. Paclitaxel treatment did not alter the compound action potentials or conduction velocity of C-fibers. The stimulated release of CGRP from the central terminals in the spinal cord was not altered in paclitaxel-injected animals. These results suggest that paclitaxel affects the peripheral endings of sensory neurons to alter transmitter release, and this may contribute to the symptoms seen in neuropathy.
\end{abstract}

\footnotetext{
() 2010 Published by Elsevier Inc.

${ }^{8}$ Correspondence and reprints should be addressed to: Dr. Michael Vasko, Department of Pharmacology and Toxicology, Indiana University School of Medicine, 635 Barnhill Dr., A401, Indianapolis, IN 46202, Phone: 317-274-7844, Fax: (317) 274-7714, vaskom@iupui.edu.

5 Financial support for this work was provided by National Cancer Institute CA121168 to M.R.K

${ }^{6}$ National Institute of Neuorlogical Diseases and Stroke Health NS048565 to M.R.V.

${ }^{7}$ National Institute of Neuorlogical Diseases and Stroke Health NS053422 to T.R.C.

${ }^{9}$ These studies were conducted in a facility constructed with the support from Research Facilities Improvement Program Grant Number C06 RR015481-01 from the National Center for Research Resources, National Institutes of Health (M.R.V.).

Conflict of Interest statement:

The authors declare that there are no conflicts of interest.

Publisher's Disclaimer: This is a PDF file of an unedited manuscript that has been accepted for publication. As a service to our customers we are providing this early version of the manuscript. The manuscript will undergo copyediting, typesetting, and review of the resulting proof before it is published in its final citable form. Please note that during the production process errors may be discovered which could affect the content, and all legal disclaimers that apply to the journal pertain.
} 


\section{Keywords}

paclitaxel; calcitonin gene-related peptide; vasodilatation; sensory neurons; peripheral neuropathy

\section{Introduction}

Peripheral neuropathy is a common side effect resulting from treatment with the cancer chemotherapeutic drug paclitaxel. This neuropathy is characterized by intense pain in the extremities, tingling, numbness (paraesthesia), a paradoxical burning pain in response to cold temperatures, and loss of proprioception (Briasoulis et al., 2002, Dina et al., 2001, Dougherty et al., 2004, Forsyth et al., 1997, Lipton et al., 1989, Wiernik et al., 1987). Neurophysiologic examination of patients with paclitaxel-induced peripheral neuropathy reveals a decrease in sensory nerve conduction velocity and compound action potential amplitude (Augusto et al., 2008, Dougherty et al., 2004, Sahenk et al., 1994). With successive courses of treatment, the symptoms can become more severe, requiring either a reduction in dose or cessation of therapy. Although there are treatments available for the non-neurological side effects produced by paclitaxel (Sarosy et al., 1992), there are currently no viable treatments to prevent or alleviate the neuropathy.

To study the mechanisms associated with paclitaxel-induced peripheral neuropathy, investigators have injected paclitaxel systemically in animals and examined various endpoints to model symptoms of neuropathy observed in humans. Depending on the magnitude of the dose, the injection schedule, and the end-points measured, the data reveal either a decrease or an increase in sensory neuronal function. For example, in studies using relatively higher doses of paclitaxel, an antinociceptive effect was observed (Apfel et al., 1991, Authier et al., 2000, Cavaletti et al., 1997, Cavaletti et al., 1995), while in studies using relatively lower doses, hypernociception was seen (Dina et al., 2001, Polomano et al., 2001, Weng et al., 2005). Moreover, the higher doses that produced antinociception often produced a decrease in sensory nerve action potential amplitude which is accompanied by morphological changes in the sensory nerves (Authier et al., 2000, Campana et al., 1998, Cavaletti et al., 1995). In contrast, lower doses that produced hypernociception did not cause morphological changes in the axons of the sensory nerves (Flatters and Bennett, 2006).

The various symptoms experienced by patients could result from impaired function of both myelinated and unmyelinated fibers. For example, based on symptoms reported by patients receiving paclitaxel, Dougherty et al postulated that myelinated fiber function is impaired, while function of the unmyelinated fibers is preserved (Dougherty et al., 2004). Additionally, studies in animals revealed a pathology of myelinated fibers in electron micrographs (Cliffer et al., 1998), while changes in the mechanical threshold or conduction velocity of $\mathrm{C}$ fibers were absent following systemic administration of paclitaxel (Dina et al., 2001). In contrast, a sural nerve biopsy from a patient receiving paclitaxel showed degeneration of both myelinated and unmyelinated fibers (Sahenk et al., 1994), and at least one animal study revealed degeneration of myelinated and unmyelinated fibers alike (Authier et al., 2000). Because the hypernociception observed following systemic administration with paclitaxel suggests involvement of the small diameter peptidergic fibers [lightly myelinated $\mathrm{A} \delta$ and unmyelinated C-fibers), we asked if the function of these fibers is altered after systemic administration of paclitaxel. We addressed this question by examining the release of the neuropeptide calcitonin gene related peptide (CGRP) from sensory nerve endings. Because release of CGRP from the peripheral endings of primary afferent sensory neurons mediates vasodilatation (Brain et al., 1986, Brain et al., 1985, Chin et al., 1994), we therefore examined alterations in blood flow in the skin of rats that were administered multiple injections of $1 \mathrm{mg} / \mathrm{kg}$ paclitaxel (Polomano et al., 2001). We also 
examined the release of CGRP from sensory nerve terminals in the dorsal spinal cord since this release likely contributes to an increase in the perception of noxious stimuli. Portions of this work have been published in abstract form (Gracias et al., 2008).

\section{Materials and Methods}

\subsection{Materials}

For all animal studies, male Sprague Dawley rats were used. The rats were housed in group cages in a light controlled room (light from 6:00 to 19:00) at a constant temperature of $22^{\circ}$ C. Food and water were available ad libitum. The Animal Care and Use Committee at Indiana University School of Medicine, Indianapolis, IN approved all procedures used in these studies. A stock concentration of $10 \mathrm{mg} / \mathrm{ml}$ paclitaxel in dimethyl sulfoxide (DMSO) (Sigma Chemical Company, St. Louis, MO) was prepared and stored at $-20^{\circ} \mathrm{C}$ and was further diluted to $1 \mathrm{mg} / \mathrm{ml}$ in phosphate buffered saline (PBS) such that the final concentration of DMSO was 10\%. Rats initially weighing 175-200 grams were administered $1 \mathrm{mg} / \mathrm{kg}$ paclitaxel intraperitoneally (i.p) every other day for a total of four doses (Polomano et al., 2001). We chose this dosage regimen since this dosing schedule and route of administration produced nociceptive behavior in rats without producing overt morphological changes in sensory neurons (Polomano et al., 2001). Previous work also demonstrates that the i.p. route of administration results in a significantly higher concentration of paclitaxel in the serum and in tissues 6-24 hours after administration of a single dose of $5 \mathrm{mg} / \mathrm{kg}$ compared to the same dose delivered intravenously (Soma et al., 2009). Additionally, based on clinical trials, i.p paclitaxel administered to women with ovarian cancer has greater therapeutic benefits than intravenous administration (Francis et al., 1995). Thus, i.p administration of paclitaxel is an easy but valid way to administer the drug.

Control groups received an intra-peritoneal injection of $10 \%$ DMSO in PBS. Even though cremophor EL+ ethanol is the vehicle used in the clinic, we preferred to use 10\% DMSO because of a concern that the ethanol in the vehicle formulation injection could alter the sensitivity of sensory neurons. Furthermore, previous studies have shown that i.p administration of $10 \%$ DMSO as a vehicle does not produce any change in sensory behavior (Polomano et al., 2001).

\subsection{Measurement of blood flow}

Initial experiments to examine changes in blood flow were performed as previously described (Shrestha et al., 2009). Briefly, rats were anesthetized with $100 \mathrm{mg} / \mathrm{kg}$ sodium thiopental and the hair on the dorsal hindpaw shaved. The rats were placed on a heated $\left(37^{\circ} \mathrm{C}\right)$ platform to maintain body temperature. Blood flow was measured using a BLF21D laser Doppler flowmeter from Transonic systems Inc. (Ithaca, NY) and a type N 11 G needle-style probe gently placed in contact with the hindpaw using a micromanipulator. This system measures activity of red blood cell flux in $\sim 2 \mathrm{~mm}^{3}$ area beneath the probe (Rendell et al., 1998). Voltage output corresponding to tissue perfusion units (TPUs) were recorded on-line using Biopac data acquisition system (Goleta, CA). Vasodilatation was induced by intradermal injection of capsaicin, methacholine (Sigma Chemical Company, St. Louis, MO) or $\alpha$-CGRP (Bachem). The other hindpaw of the rat received the vehicle, $0.01 \%$ MPL (Aldrich Chemical Co., Milwaukee, WI). Injections were made $1 \mathrm{~mm}$ away for the probe site by inserting a $27 \mathrm{G}$ needle into the skin at an angle of $\sim 15$ degrees and the injection volume was $1 \mu \mathrm{l}$.

To examine vasodilatation in response to sciatic nerve stimulation, an initial baseline was recorded, after which the sciatic nerve was exposed at the mid-thigh level. To prevent injury-induced action potentials, $1 \%$ lidocaine was applied to the proximal end of the sciatic 
nerve for 2 minutes. The nerve was cut $2 \mathrm{~mm}$ distal to the lidocaine application site and was placed into a nerve cuff fitted with a silver-stimulating electrode. A layer of petroleum jelly was applied over the stimulating electrode, the skin was sutured, and the animal was returned to the heated platform. Baseline blood flow following axotomy was recorded for 30 minutes to allow sufficient time for the lidocaine block to be extinguished, then a stimulus amplitude of $5 \mathrm{~mA}$ at $10 \mathrm{~Hz}$ for 30 seconds was used to induce vasodilatation (Koltzenburg et al., 1990).

To examine if the stimulation-induced vasodilatation in the hindpaw was mediated by CGRP, $20 \mu \mathrm{M}$ of the CGRP receptor antagonist, CGRP $_{8-37}$, was injected 5 minutes before application of stimulus.

\subsection{Neuropeptide release from spinal cord slices}

For experiments measuring release of CGRP from spinal cord slices, male Sprague Dawley rats were injected with paclitaxel or vehicle, were sacrificed, spinal cord slices were prepared, and release of CGRP was quantified by radioimmunoassay as previously described (Chen et al., 1996). The amount of peptide released was expressed as \% total content of iCGRP/min.

\subsection{Compound Action Potential Recording of Rat Sciatic Nerve Preparations}

After treatment with vehicle or paclitaxel, rats were sacrificed and the sciatic nerves were dissected and cut to $21 \mathrm{~mm}$ in length. Compound action potentials (CAPs) were recorded as previously described (Bulaj et al., 2006). Briefly, the nerves were placed in a recording chamber made from Sylgard (Dow Chemical, Midland, MI) with a linear array of 4 circular wells. Each well ( $4 \mathrm{~mm}$ diameter by $4 \mathrm{~mm}$ deep; $50 \mu \mathrm{L}$ volume) was separated from its neighboring well by a $1-2 \mathrm{~mm}$ partition. Vaseline was used on the partitions between the wells to provide electrical isolation. Wells were filled with a HEPES-buffered saline solution consisting of $140 \mathrm{mM} \mathrm{NaCl}, 3 \mathrm{mM} \mathrm{KCl}, 1 \mathrm{mM} \mathrm{MgCl}_{2}, 1 \mathrm{mM} \mathrm{CaCl}_{2}$, and $10 \mathrm{mM}$ HEPES (pH 7.3). Silver wire stimulating electrodes were placed in the first two wells. The second well also contained a ground electrode. Silver wire recording electrodes were placed in the third and fourth wells. Stimuli $(0.01$ to $10 \mathrm{~mA} \times 1 \mathrm{~ms})$ were applied to evoke CAPs. The CAPs were recorded with a DP-311 differential amplifier (Warner Instruments, Hamden, CT), were band-pass filtered ( $1 \mathrm{~Hz}$ to $3 \mathrm{kHz}$ ), and were digitized (10 kHz sampling frequency) using a LabTrax-4/16 data acquisition system (World Precision Instruments, Sarasota, FL). Conduction velocity was estimated by measuring the latency from a $5 \mathrm{~mA}$ stimulus to the peak of the negative $\mathrm{C}$-wave and dividing by the distance between the stimulus and recording electrodes $(15 \mathrm{~mm})$. Recordings were conducted at room temperature $\left(\sim 22^{\circ} \mathrm{C}\right)$.

\subsection{Data Analysis}

The data for all blood flow experiments were represented as the mean response \pm SEM recorded per 3-minutes as tissue perfusion units (TPU) for each animal. To determine if there were statistically significant differences in stimulus-induced increases in blood flow between treatment groups, we compared the mean \pm SEM of the evoked response/15 minutes between treatment groups using one-way analysis of variance (ANOVA) and Bonferroni's post hoc test. Evoked response was calculated by subtracting the baseline response/15 minutes from the stimulated response/15 minutes.

Release data from spinal cord slices are expressed as the mean \pm SEM of the fractional release of iCGRP (\% of total content). For analysis of CGRP release from spinal cord slices, the sum of the iCGRP released in the 3 fractions before exposure to the stimulus (basal release/9 minutes) was subtracted from the sum of the iCGRP released in the 3 fractions 
during exposure to the stimulus (stimulated release/9 minutes) to give the evoked release of iCGRP in 9 minutes (evoked release/9 minutes). The evoked release between control and paclitaxel-treated rats was compared using an unpaired t test. In all cases, statistical significance was set at $p<0.05$.

\section{Results}

\subsection{Characterization of vasodilatation after activation of sensory neurons}

We performed an initial series of experiments to establish a model for capsaicin-induced vasodilatation in the dorsal hindpaw of the rat a manner analogous to previous studies (Brain et al., 1985, Jansen et al., 1989, and see review by Richardson and Vasko, 2002). Figures 1A (left panel) and 1B show that intradermal injection of $10 \mu \mathrm{M}$ capsaicin increased blood flow from $53 \pm 7$ TPU/15 min to $121 \pm 15$ TPU/15 minutes. Although not shown in the figure, intradermal injection of the vehicle for capsaicin (0.1\% MPL in PBS) did not increase blood flow over the basal value ( $68 \pm 6$ TPU/15 minutes for basal and $70 \pm 10$ TPU/15 minutes after vehicle).

To demonstrate that the capsaicin-induced vasodilatation is mediated by CGRP, we determined whether the CGRP1 receptor antagonist CGRP $_{8-37}$ (Chiba et al., 1989, Chu et al., 2001) could attenuate the effects of capsaicin. When $20 \mu \mathrm{M}$ of CGRP $8-37$ was injected intradermally five minutes before capsaicin, the increase in blood flow was blocked (figures 1A, right panel, and 1B). The capsaicin-evoked blood flow was $68 \pm 11$ TPU/15 minutes in the absence of $\mathrm{CGRP}_{8-37}$; whereas in the presence of $\mathrm{CGRP}_{8-37}$ the evoked response was -4 \pm 5 TPU/15 minutes (figure 1C). We next performed a concentration response curve for the capsaicin-induced increase in blood flow utilizing concentrations ranging from $300 \mathrm{nM}$ to 1 $\mathrm{mM}$. Figure 1D illustrates that intradermal capsaicin increased blood flow in a dosedependent manner, and the EC50 from this curve was $12 \mu \mathrm{M}$. We used $10 \mu \mathrm{M}$ capsaicin in subsequent studies because this concentration is on the linear region of the curve.

We also characterized the ability of electrical stimulation of the sciatic nerve to induce vasodilatation using a stimulus of $5 \mathrm{~mA}$ at $10 \mathrm{~Hz}$ for 30 seconds. We chose this stimulation paradigm since it activates the unmyelinated, slow conducting $\mathrm{C}$ fibers and the thinly myelinated A $\delta$ fibers (Koltzenburg et al., 1990). The basal blood flows before and after axotomy was not significantly different (figure $2 \mathrm{~A}$ ). Following electrical stimulation of the sciatic nerve, there was a robust increase in blood flow (figures 2A, left panel and 2B). The response over $15 \mathrm{~min}$ increased from a basal value of $103 \pm 15 \mathrm{TPU} / 15$ minutes to $329 \pm 8$ TPU/15 minutes (figure 2B). The average evoked response obtained by subtracting the basal response from the stimulated response was $226 \pm 19$ TPU/15 minutes (figure 2C).

In the presence of $20 \mu \mathrm{M}$ CGRP $_{8-37}$, electrical stimulation did not result in a significant increase in blood flow over time (figure $2 \mathrm{~A}$, right panel). The average evoked response in the presence of the antagonist was $14 \pm 10 \mathrm{TPU} / 15$ minutes, which was significantly different from that recorded in response to electrical stimulation in the absence of CGRP $_{8-37}$ (figure 2C). Injection of $\mathrm{CGRP}_{8-37}$ alone did not alter blood flow. The average evoked response to the intradermal injection of $\mathrm{CGRP}_{8-37}$ was $-4 \pm 13 \mathrm{TPU} / 15$ minutes.

\subsection{Chronic administration of paclitaxel reduces vasodilatation caused by stimulation of sensory neurons}

We next determined the effects of chronic administration of paclitaxel on vasodilatation induced by either capsaicin or electrical stimulation. As observed in control experiments, the intradermal injection of $10 \mu \mathrm{M}$ capsaicin in the hindpaw of rats injected with vehicle increased the blood flow over 3-fold from a basal value of $88 \pm 4$ to $277 \pm 19$ TPU/15 minutes (Figures 3A, left panel and 3B). In paclitaxel-treated animals, the blood flow 
increased from $82 \pm 6$ to $158 \pm 16$ TPU/15 minutes (figures 3A, right panel, and 3B). The capsaicin-evoked response was $190 \pm 19$ TPU/15 minutes in vehicle-treated animals, while in paclitaxel-treated animals the capsaicin-evoked response was $76 \pm 17$ TPU/15 minutes (figure 3C). These data indicate that paclitaxel significantly decreased vasodilatation in the hindpaw in response to capsaicin.

Paclitaxel treatment also significantly reduced the ability of electrical stimulation of the sciatic nerve to increase blood flow. After stimulation of the sciatic nerve in vehicle-treated animals, the blood flow increased over 3-fold from $128 \pm 21$ to $426 \pm 24$ TPU/15 minutes (figures 4A, left panel and 4B). In paclitaxel-treated rats however, sciatic nerve stimulation induced only a 2-fold increase in blood flow from $145 \pm 19 \mathrm{TPU} / 15 \mathrm{~min}$ to $296 \pm 28 \mathrm{TPU} /$ 15 minutes (Figures 4A, right panel, and 4B). The evoked response in paclitaxel-treated animals was approximately half of the evoked release in vehicle-treated rats (298 $\pm 30 \mathrm{TPU} /$ $15 \mathrm{~min}$ for vehicle versus $151 \pm 13 \mathrm{TPU} / 15$ minutes for paclitaxel treated (figure 4C).

\subsection{Chronic administration of paclitaxel does not affect CGRP-induced or methacholine- induced vasodilatation}

It is possible that chronic treatment with paclitaxel alters the expression of CGRP receptors on vascular smooth muscle or has a direct action to prevent muscle relaxation. To examine these possibilities, we determined whether chronic administration of paclitaxel altered vasodilatation induced by direct injection into the dorsal hindpaw of CGRP or the nonselective muscarinic receptor agonist methacholine (Kimura et al., 2007).

When $30 \mu \mathrm{M}$ of CGRP was injected intradermally, the blood flow increased from a basal value of $97 \pm 11 \mathrm{TPU} / 15 \mathrm{~min}$ to $316 \pm 14 \mathrm{TPU} / 15$ min (figures 5A, left panel and 5B). In paclitaxel injected animals, the CGRP-induced vasodilatation was not significantly different from control animals; blood flow increased from $96 \pm 15$ to $302 \pm 8$ TPU/15 min (figures $5 \mathrm{~A}$, right panel, and 5B). The evoked response was $219 \pm 8 \mathrm{TPU} / 15 \mathrm{~min}$ for control animals and $206 \pm 15$ TPU/15 min for paclitaxel treated animals (data not shown). Intradermal injection of $100 \mu \mathrm{M}$ methacholine increased blood flow from $97 \pm 8$ to $275 \pm 11 \mathrm{TPU} / 15$ minutes (figures 5C, left panel, and 5D) in vehicle-treated animals. In paclitaxel-treated animals, methacholine increased blood flow from $88 \pm 8$ to $290 \pm 23$ TPU/15 minutes (figures 5C, right panel, and 5D). The methacholine-evoked response was not significantly different between the two groups of animals ( $178 \pm 15$ TPU/15 minutes and $201 \pm 23$ TPU/ 15 minutes in vehicle-treated or paclitaxel-treated animals respectively (data not shown).

\subsection{Chronic administration of paclitaxel does not alter C-fiber conduction in rat sciatic nerves}

To measure CAPs and conduction velocity in small diameter C-fibers, sciatic nerves from vehicle-treated $(n=6)$ and paclitaxel-treated $(n=6)$ rats were stimulated with $1 \mathrm{~ms}$ duration current pulses ranging from 0.01 to $10 \mathrm{~mA}$. No significant difference was observed in the CAPs (figures 6A and 5B) or the minimum current needed to elicit detectable C-fiber CAPs between sciatic nerves from vehicle treated rats $(\mathrm{n}=12)$ and nerves from paclitaxel-treated rats $(\mathrm{n}=11 ; 2.1 \pm 0.4$ and $2.0 \pm 0.1 \mathrm{~mA}$, respectively). Similarly, no significant difference was detected for the latency from the $5 \mathrm{~mA}$ stimulus to the peak of the positive $\mathrm{C}$-wave (data not shown). The amplitude of the $\mathrm{C}$-wave was also examined by measuring the voltage difference between the peak of the negative $\mathrm{C}$-wave and the peak of the positive $\mathrm{C}$-wave. Although the amplitude of the $\mathrm{C}$-wave was $59 \pm 13 \mu \mathrm{V}$ for control nerves and $84 \pm 13 \mu \mathrm{V}$ for nerves from paclitaxel-treated rats, this difference was not significant. The conduction velocities also were not significantly different between nerves of vehicle-treated animals $(0.68 \pm 0.09 \mathrm{~m} / \mathrm{s} ; \mathrm{n}=12)$ and those from paclitaxel-treated rats $(0.67 \pm 0.04 \mathrm{~m} / \mathrm{s} ; \mathrm{n}=11$; figure 
5C). Overall, these data indicate that the paclitaxel treatment used in these experiments does not significantly alter $\mathrm{C}$-fiber conduction in rat sciatic nerves.

\subsection{Chronic administration of paclitaxel does not alter the release of iCGRP from dorsal spinal cord}

We also examined the effects of chronic exposure of paclitaxel on iCGRP release from the terminals of sensory neurons in the dorsal spinal cord. The basal release of iCGRP/9 minutes in the vehicle-injected group was $0.77 \pm 0.1 \%$ of total content/9 minutes, whereas $500 \mathrm{nM}$ capsaicin significantly increased the release to $4.5 \pm 0.5 \%$ of total content $/ 9$ minutes (figures 7A, left panel, and 7B). Chronic administration of paclitaxel did not significantly alter either the basal or the capsaicin-stimulated release. Basal release in paclitaxel-treated animals was $0.67 \pm 0.07 \%$ content/9 minutes, while stimulated release was $3.6 \pm 0.5 \%$ content/9 minutes (figures 7A, right panel, and 7B). The evoked release was $3.8 \pm 0.5 \%$ content $/ 9$ minutes and $2.9 \pm 0.5 \%$ content $/ 9$ minutes in the vehicle-injected group and the paclitaxel-injected group, respectively (figure 7C). The total content of CGRP in the tissue from vehicle-injected animals was $505.9 \pm 33.8$ and that from paclitaxel-treated animals was $496.8 \pm 30.6 \mathrm{fmol} / \mathrm{mg}$ of tissue, suggesting that paclitaxel treatment did not alter CGRP content in the spinal cord tissues.

The lack of significant differences in the release of iCGRP evoked by capsaicin may be attributed to the dose of paclitaxel used. Therefore, we also examined the release of iCGRP from spinal cord slices from animals that were treated with $2 \mathrm{mg} / \mathrm{kg}$ paclitaxel every other day for 4 doses. Using this dosing schedule, we did not observe any significant alteration in the basal or stimulated release of iCGRP, although there was a trend for the capsaicinstimulated release to be lower. The evoked release in rats treated with vehicle was $3.9 \pm 0.6$ $\%$ of content $/ 9 \mathrm{~min}(\mathrm{n}=10)$, while evoked release in animals receiving $2 \mathrm{mg} / \mathrm{kg}$ paclitaxel was $2.3 \pm 0.6 \%$ of content $/ 9 \min (n=8)$.

\section{Discussion}

The data presented above demonstrate that systemic administration of paclitaxel reduces the ability of small diameter sensory neurons to increase peripheral blood flow in the dorsal hindpaw of the rat through an action of the drug on the peripheral endings of the sensory neurons. This is based on the observation that paclitaxel reduced vasodilatation induced by intradermal injection of capsaicin or by antidromic stimulation of the sciatic nerve.

Capsaicin activates TRPV1 receptors on small diameter sensory neurons allowing calcium to enter, and this increases the release of neuropeptides from a subset of these neurons. Electrical stimulation at $5 \mathrm{~mA}$ at $10 \mathrm{~Hz}$ for 30 seconds depolarizes all sensory neurons, including the low threshold myelinated fibers and the high threshold peptidergic $\mathrm{A} \delta$ and $\mathrm{C}$ fibers (Koltzenburg et al., 1990). The generated action potentials travel antidromically to the peripheral endings where the depolarization activates voltage-gated calcium channels and causes transmitter release. Because administration of the CGRP antagonist CGRP8-37 completely attenuates the effects of capsaicin and electrical stimulation, vasodilatation is mediated by CGRP and involvement of the sympathetic nervous system seems unlikely.

It also is highly unlikely that the paclitaxel-induced vasodilatation is secondary to a direct effect on blood vessels in the hindpaw since the increase in blood flow produced by methacholine acting at muscarinic receptors on the smooth muscle of blood vessels (Kimura et al., 2007) is not affected by paclitaxel administration. In addition, systemic administration of paclitaxel does not alter vasodilatation by intradermal injection of CGRP, strongly suggesting that CGRP receptors on blood vessels are unaffected. Together these data strongly support the notion that paclitaxel is diminishing the function of sensory nerve endings by acting on the nerve terminal and not via post-synaptic sites. 
The fact that paclitaxel has a similar action using two different stimuli (i.e. capsaicin and electrical stimulation) provide complementary data showing that the anticancer drug is affecting the sensory nerve ending in the periphery. With electrical stimulation, it is possible that paclitaxel could diminish conduction velocity of sensory neurons. However, we did not observe any significant alteration in the conduction velocity of C-fibers or changes in the CAPs. Although some previous studies have shown that large doses of paclitaxel can reduce conduction velocity of sensory neurons (see below), studies with lower doses show no effect on conduction velocity (Cavaletti et al., 1995, Dina et al., 2001). Based on our data and these studies, it is unlikely that the paclitaxel-induced decease in the ability of sensory nerve stimulation to increase blood flow is secondary to altered nerve conduction.

In contrast to the effects of paclitaxel on peripheral endings of small diameter sensory neurons, chronic administration of $1 \mathrm{mg} / \mathrm{kg}$ or $2 \mathrm{mg} / \mathrm{kg}$ of the drug does not affect release of iCGRP from central terminals of primary afferent sensory neurons. Furthermore, we did not observe any difference in the total CGRP content in the spinal cord slices from either paclitaxel-treated animals or from vehicle-injected animals, a finding that is consistent with previous examination of CGRP content in paclitaxel-treated rats (Schmidt et al., 1995). The lack of effect at central terminals could be secondary to the inability of paclitaxel to enter the central nervous system in sufficient quantities to affect the nerve endings in the spinal cord. This possibility is supported by the observations of Cavaletti and co-workers that one day after the last of 5 doses of $5 \mathrm{mg} / \mathrm{kg}$ of paclitaxel on different days, the levels of the drug measured in the spinal cord were low, while levels in the sciatic nerve and dorsal root ganglia were '5-fold and '30-fold higher, respectively (Cavaletti et al., 2000). Because sensory neurons are pseudouniploar with cell bodies in the dorsal root ganglia and a single axon extending from the periphery to the dorsal spinal cord, accumulation of the drug at the cell bodies could be expected to affect the entire neuron (i.e. alter release at both central and peripheral endings of the neurons). The fact that we did not observe a change in release at the central terminals of sensory neurons suggests that the actions of paclitaxel occur at peripheral endings and does not act on the cell bodies to reduce the expression of CGRP.

Paclitaxel-induced peripheral neuropathy is largely sensory, can be long lasting (Lipton et al., 1989, Mielke et al., 2005), and no treatments are available to prevent or reverse the neurotoxicity. As a result, a number of investigators have examined the effects of various dosing regimens of paclitaxel on a number of endpoints in animal models including sensory nerve conduction (Authier et al., 2000, Cavaletti et al., 1997, Cavaletti et al., 1995, Cliffer et al., 1998, Persohn et al., 2005), nociceptive behavior (Authier et al., 2000, Persohn et al., 2005, Peters et al., 2007, Polomano et al., 2001), and morphological changes in sensory neurons (Authier et al., 2000, Cavaletti et al., 1997, Cavaletti et al., 1995, Cliffer et al., 1998, Persohn et al., 2005). In most of these studies, the severity of change in neuronal function is dependent on the total amount of paclitaxel administered. For example, in a number of studies using relatively high cumulative doses of paclitaxel, i.e. greater than 16 $\mathrm{mg} / \mathrm{kg}$, rats show a decreased sensory nerve conduction velocity and a reduced response to noxious thermal or mechanical stimulation accompanied by a change in morphology of sensory nerves. In studies using lower doses of paclitaxel administered over time, the drug produces hyperalgesia and mechanical allodynia that models neuropathic pain syndromes in the absence of visible signs of nerve damage (Dina et al., 2001, Polomano et al., 2001, Weng et al., 2005). In the current work, we examined vasodilatation in the dorsal hindpaw induced by stimulation of sensory neurons as a way to assess the effects of paclitaxel on a functional endpoint in a subset of peptidergic sensory neurons. Using vasodilatation as an endpoint, it is clear that a dosing regimen that produces hypersensitivity to noxious stimulation (Dina et al., 2001, Polomano et al., 2001, Weng et al., 2005) also decreases peripheral blood flow. Thus, an apparent inconsistency exists between our results showing diminished function of peptidergic sensory neurons and studies measuring nociceptive 
behaviors. It is possible that the changes in nociception measured by others reflect alterations in the central pain pathway rather than in sensory neurons. This possibility is supported by the observation that the dosing regimen we used also decreases glutamate transporters in the dorsal spinal cord (Weng et al., 2005), which could produce a central sensitization. Paclitaxel treatment also increases the activity and noxious stimulus-induced afterdischarge in spinal cord neurons (Cata et al., 2006). Alternatively, the diminished blood flow in the periphery could mimic an ischemic condition which results in decreased local $\mathrm{pH}$ and a consequent activation of sensory neurons to produce hyperalgesia (Steen and Reeh, 1993, Steen et al., 1992). Finally, paclitaxel could have a differential effect on nonpeptidergic sensory neurons that could contribute to pain sensation and further experiments are warranted to determine effects of paclitaxel on glutamate release from sensory neurons. It is intriguing to speculate that paclitaxel-induced neuropathy in humans might involve components of both a decrease and an increase in sensory neuronal function.

The question remains, however, how paclitaxel causes diminished function of sensory neurons. Paclitaxel's primary mechanism of action is the induction of microtubule polymerization by binding to $\beta$-tubulin with a subsequent stabilization that eventually leads to inhibition of microtubule function (Schiff et al., 1979, Schiff and Horwitz, 1980). This mechanism appears to account for the ability of paclitaxel to inhibit cell division in dividing cells, but in post-mitotic cells this action could inhibit axonal transport of organelles and the growth of neurites in neuronal cells (Ligon and Steward, 2000, Morris and Hollenbeck, 1995, Sato-Harada et al., 1996, Tsui et al., 1984). Thus, three major mechanisms could account for the ability of paclitaxel to diminish the function of peripheral endings of sensory neurons. First, paclitaxel could affect axonal transport and thus diminish the amount of CGRP that can be transported to nerve terminals. This seems unlikely since the content of CGRP in central terminals of sensory neurons is not affected by paclitaxel treatment. Paclitaxel could also be affecting the actual release mechanism in sensory nerve terminals. There is some precedent for this in the literature since paclitaxel interferes with stimulated release of noradrenalin from chromaffin cells in culture (Thuret-Carnahan et al., 1985) and with glucose-stimulated insulin release from isolated islets of Langerhans (Howell et al., 1982). The other potential mechanism is a retraction of the peripheral endings of the sensory nerves which possibly contributes to the post synaptic effects observed in our study. Retraction of nerve endings could remove CGRP from the nerve muscle synapse, thus reducing the effectiveness of CGRP in causing vasodilatation. In support of this notion, electromyography studies of patients that received a single high-dose of paclitaxel showed denervation (Iniguez et al., 1998). Siau et al also reported that animals receiving multiple injections of paclitaxel showed decreased epidermal innervation as assessed by immunostaining for the neuronal marker PGP9.5 (Siau et al., 2006). It also is possible that the effects of paclitaxel are secondary to mitochondrial damage which could adversely affect sensory nerve function. Indeed, Flatters and Bennett observed abnormalities in mitochondrial morphology in sciatic nerves from animals injected with multiple doses of 2 $\mathrm{mg} / \mathrm{kg}$ paclitaxel (Flatters and Bennett, 2006). In addition, paclitaxel exposure results in abnormalities in mitochondrial morphology in human neuroblastoma cells resulting in increased production of reactive oxygen species (Andre et al., 2002). Further studies are clearly warranted to assess functional damage to mitochondria in sensory nerves following treatment with paclitaxel.

There are many consequences to decreased presynaptic function of sensory neurons. For example, vasodilatation after activation of small diameter sensory neurons is important for the delivery of leukocytes and other immune cells to the site of injury, and is involved in tissue repair and wound healing. More importantly, neurogenic control of skin blood flow is important for temperature regulation of the skin, and the lack of it might contribute to the coldness in the extremities experienced by patients. In summary, the current study 
demonstrates that systemic administration of paclitaxel causes a decrease in the release of CGRP from peripheral terminals of sensory nerves. The use of changes in blood-flow to measure functional changes in small diameter sensory neurons has much value for basic research in the mechanisms of drug-induced neuropathy.

\section{Reference list}

Andre N, Carre M, Brasseur G, Pourroy B, Kovacic H, Briand C, et al. Paclitaxel targets mitochondria upstream of caspase activation in intact human neuroblastoma cells. FEBS Lett 2002;532:256-60. [PubMed: 12459501]

Apfel SC, Lipton RB, Arezzo JC, Kessler JA. Nerve growth factor prevents toxic neuropathy in mice. Ann Neurol 1991;29:87-90. [PubMed: 1705109]

Augusto C, Pietro M, Cinzia M, Sergio C, Sara C, Luca G, et al. Peripheral neuropathy due to paclitaxel: study of the temporal relationships between the therapeutic schedule and the clinical quantitative score (QST) and comparison with neurophysiological findings. J Neurooncol 2008;86:89-99. [PubMed: 17611715]

Authier N, Gillet JP, Fialip J, Eschalier A, Coudore F. Description of a short-term Taxol-induced nociceptive neuropathy in rats. Brain Res 2000;887:239-49. [PubMed: 11134612]

Brain SD, Tippins JR, Morris HR, MacIntyre I, Williams TJ. Potent vasodilator activity of calcitonin gene-related peptide in human skin. J Invest Dermatol 1986;87:533-6. [PubMed: 2428885]

Brain SD, Williams TJ, Tippins JR, Morris HR, MacIntyre I. Calcitonin gene-related peptide is a potent vasodilator. Nature 1985;313:54-6. [PubMed: 3917554]

Briasoulis E, Karavasilis V, Tzamakou E, Haidou C, Piperidou C, Pavlidis N. Pharmacodynamics of non-break weekly paclitaxel (Taxol) and pharmacokinetics of Cremophor-EL vehicle: results of a dose-escalation study. Anticancer Drugs 2002;13:481-9. [PubMed: 12045459]

Bulaj G, Zhang MM, Green BR, Fiedler B, Layer RT, Wei S, et al. Synthetic muO-conotoxin MrVIB blocks TTX-resistant sodium channel NaV1.8 and has a long-lasting analgesic activity. Biochemistry 2006;45:7404-14. [PubMed: 16752929]

Campana WM, Eskeland N, Calcutt NA, Misasi R, Myers RR, O'Brien JS. Prosaptide prevents paclitaxel neurotoxicity. Neurotoxicology 1998;19:237-44. [PubMed: 9553960]

Cata JP, Weng HR, Chen JH, Dougherty PM. Altered discharges of spinal wide dynamic range neurons and down-regulation of glutamate transporter expression in rats with paclitaxel-induced hyperalgesia. Neuroscience 2006;138:329-38. [PubMed: 16361064]

Cavaletti G, Cavalletti E, Montaguti P, Oggioni N, De Negri O, Tredici G. Effect on the peripheral nervous system of the short-term intravenous administration of paclitaxel in the rat. Neurotoxicology 1997;18:137-45. [PubMed: 9215996]

Cavaletti G, Cavalletti E, Oggioni N, Sottani C, Minoia C, D’Incalci M, et al. Distribution of paclitaxel within the nervous system of the rat after repeated intravenous administration. Neurotoxicology 2000;21:389-93. [PubMed: 10894128]

Cavaletti G, Tredici G, Braga M, Tazzari S. Experimental peripheral neuropathy induced in adult rats by repeated intraperitoneal administration of taxol. Exp Neurol 1995;133:64-72. [PubMed: 7601264]

Chen JJ, Barber LA, Dymshitz J, Vasko MR. Peptidase inhibitors improve recovery of substance P and calcitonin gene-related peptide release from rat spinal cord slices. Peptides 1996;17:31-7. [PubMed: 8822507]

Chiba T, Yamaguchi A, Yamatani T, Nakamura A, Morishita T, Inui T, et al. Calcitonin gene-related peptide receptor antagonist human CGRP-(8-37). Am J Physiol 1989;256:E331-5. [PubMed: 2537579]

Chin SY, Hall JM, Brain SD, Morton IK. Vasodilator responses to calcitonin gene-related peptide (CGRP) and amylin in the rat isolated perfused kidney are mediated via CGRP1 receptors. J Pharmacol Exp Ther 1994;269:989-92. [PubMed: 8014885]

Chu DQ, Legon S, Smith DM, Costa SK, Cuttitta F, Brain SD. The calcitonin gene-related peptide (CGRP) antagonist CGRP(8-37) blocks vasodilatation in inflamed rat skin: involvement of adrenomedullin in addition to CGRP. Neurosci Lett 2001;310:169-72. [PubMed: 11585594] 
Cliffer KD, Siuciak JA, Carson SR, Radley HE, Park JS, Lewis DR, et al. Physiological characterization of Taxol-induced large-fiber sensory neuropathy in the rat. Ann Neurol 1998;43:46-55. [PubMed: 9450768]

Dina OA, Chen X, Reichling D, Levine JD. Role of protein kinase Cepsilon and protein kinase A in a model of paclitaxel-induced painful peripheral neuropathy in the rat. Neuroscience 2001;108:50715. [PubMed: 11738263]

Dougherty PM, Cata JP, Cordella JV, Burton A, Weng HR. Taxol-induced sensory disturbance is characterized by preferential impairment of myelinated fiber function in cancer patients. Pain 2004;109:132-42. [PubMed: 15082135]

Flatters SJ, Bennett GJ. Studies of peripheral sensory nerves in paclitaxel-induced painful peripheral neuropathy: evidence for mitochondrial dysfunction. Pain 2006;122:245-57. [PubMed: 16530964]

Forsyth PA, Balmaceda C, Peterson K, Seidman AD, Brasher P, DeAngelis LM. Prospective study of paclitaxel-induced peripheral neuropathy with quantitative sensory testing. J Neurooncol 1997;35:47-53. [PubMed: 9266440]

Francis P, Rowinsky E, Schneider J, Hakes T, Hoskins W, Markman M. Phase I feasibility and pharmacologic study of weekly intraperitoneal paclitaxel: a Gynecologic Oncology Group pilot Study. J Clin Oncol 1995;13:2961-7. [PubMed: 8523061]

Gracias, N.; Pu, X.; Klaunig, J.; Kelley, M.; Vasko, M. Paclitaxel treatment alters release of iCGRP and consequently contributes to decreased cutaneous blood flow. Society for Neuroscience; Washington, DC: 2008. p. 668.14

Howell SL, Hii CS, Shaikh S, Tyhurst M. Effects of taxol and nocodazole on insulin secretion from isolated rat islets of Langerhans. Biosci Rep 1982;2:795-801. [PubMed: 6129005]

Iniguez C, Larrode P, Mayordomo JI, Gonzalez P, Adelantado S, Yubero A, et al. Reversible peripheral neuropathy induced by a single administration of high-dose paclitaxel. Neurology 1998;51:868-70. [PubMed: 9748043]

Jansen G, Lundeberg T, Kjartansson J, Samuelson UE. Acupuncture and sensory neuropeptides increase cutaneous blood flow in rats. Neurosci Lett 1989;97:305-9. [PubMed: 2469996]

Kimura K, Low DA, Keller DM, Davis SL, Crandall CG. Cutaneous blood flow and sweat rate responses to exogenous administration of acetylcholine and methacholine. J Appl Physiol 2007;102:1856-61. [PubMed: 17234802]

Koltzenburg M, Lewin G, McMahon S. Increase of blood flow in skin and spinal cord following activation of small diameter primary afferents. Brain Res 1990;509:145-9. [PubMed: 2407316]

Ligon LA, Steward O. Role of microtubules and actin filaments in the movement of mitochondria in the axons and dendrites of cultured hippocampal neurons. J Comp Neurol 2000;427:351-61. [PubMed: 11054698]

Lipton RB, Apfel SC, Dutcher JP, Rosenberg R, Kaplan J, Berger A, et al. Taxol produces a predominantly sensory neuropathy. Neurology 1989;39:368-73. [PubMed: 2564647]

Mielke S, Sparreboom A, Steinberg SM, Gelderblom H, Unger C, Behringer D, et al. Association of Paclitaxel pharmacokinetics with the development of peripheral neuropathy in patients with advanced cancer. Clin Cancer Res 2005;11:4843-50. [PubMed: 16000582]

Morris RL, Hollenbeck PJ. Axonal transport of mitochondria along microtubules and F-actin in living vertebrate neurons. J Cell Biol 1995;131:1315-26. [PubMed: 8522592]

Persohn E, Canta A, Schoepfer S, Traebert M, Mueller L, Gilardini A, et al. Morphological and morphometric analysis of paclitaxel and docetaxel-induced peripheral neuropathy in rats. Eur J Cancer 2005;41:1460-6. [PubMed: 15913989]

Peters CM, Jimenez-Andrade JM, Jonas BM, Sevcik MA, Koewler NJ, Ghilardi JR, et al. Intravenous paclitaxel administration in the rat induces a peripheral sensory neuropathy characterized by macrophage infiltration and injury to sensory neurons and their supporting cells. Exp Neurol 2007;203:42-54. [PubMed: 17005179]

Polomano RC, Mannes AJ, Clark US, Bennett GJ. A painful peripheral neuropathy in the rat produced by the chemotherapeutic drug, paclitaxel. Pain 2001;94:293-304. [PubMed: 11731066]

Rendell MS, Finnegan MF, Healy JC, Lind A, Milliken BK, Finney DE, et al. The relationship of laser-Doppler skin blood flow measurements to the cutaneous microvascular anatomy. Microvasc Res 1998;55:3-13. [PubMed: 9473405] 
Richardson JD, Vasko MR. Cellular mechanisms of neurogenic inflammation. J Pharmacol Exp Ther 2002;302:839-45. [PubMed: 12183638]

Sahenk Z, Barohn R, New P, Mendell JR. Taxol neuropathy. Electrodiagnostic and sural nerve biopsy findings. Arch Neurol 1994;51:726-9. [PubMed: 7912506]

Sarosy G, Kohn E, Stone DA, Rothenberg M, Jacob J, Adamo DO, et al. Phase I study of taxol and granulocyte colony-stimulating factor in patients with refractory ovarian cancer. J Clin Oncol 1992;10:1165-70. [PubMed: 1376773]

Sato-Harada R, Okabe S, Umeyama T, Kanai Y, Hirokawa N. Microtubule-associated proteins regulate microtubule function as the track for intracellular membrane organelle transports. Cell Struct Funct 1996;21:283-95. [PubMed: 9118234]

Schiff PB, Fant J, Horwitz SB. Promotion of microtubule assembly in vitro by taxol. Nature 1979;277:665-7. [PubMed: 423966]

Schiff PB, Horwitz SB. Taxol stabilizes microtubules in mouse fibroblast cells. Proc Natl Acad Sci U S A 1980;77:1561-5. [PubMed: 6103535]

Schmidt Y, Unger JW, Bartke I, Reiter R. Effect of nerve growth factor on peptide neurons in dorsal root ganglia after taxol or cisplatin treatment and in diabetic $(\mathrm{db} / \mathrm{db})$ mice. Exp Neurol 1995;132:16-23. [PubMed: 7536686]

Shrestha S, Gracias NG, Mujenda F, Khodorova A, Vasko MR, Strichartz GR. Local antinociception induced by endothelin-1 in the hairy skin of the rat's back. J Pain 2009;10:702-14. [PubMed: 19559389]

Siau C, Xiao W, Bennett GJ. Paclitaxel- and vincristine-evoked painful peripheral neuropathies: loss of epidermal innervation and activation of Langerhans cells. Exp Neurol 2006;201:507-14. [PubMed: 16797537]

Soma D, Kitayama J, Ishigami H, Kaisaki S, Nagawa H. Different tissue distribution of paclitaxel with intravenous and intraperitoneal administration. J Surg Res 2009;155:142-6. [PubMed: 19328496]

Steen KH, Reeh PW. Sustained graded pain and hyperalgesia from harmless experimental tissue acidosis in human skin. Neurosci Lett 1993;154:113-6. [PubMed: 8361622]

Steen KH, Reeh PW, Anton F, Handwerker HO. Protons selectively induce lasting excitation and sensitization to mechanical stimulation of nociceptors in rat skin, in vitro. J Neurosci 1992;12:8695. [PubMed: 1309578]

Thuret-Carnahan J, Bossu JL, Feltz A, Langley K, Aunis D. Effect of taxol on secretory cells: functional, morphological, and electrophysiological correlates. J Cell Biol 1985;100:1863-74. [PubMed: 2581977]

Tsui HT, Lankford KL, Ris H, Klein WL. Novel organization of microtubules in cultured central nervous system neurons: formation of hairpin loops at ends of maturing neurites. J Neurosci 1984;4:3002-13. [PubMed: 6502218]

Weng HR, Aravindan N, Cata JP, Chen JH, Shaw AD, Dougherty PM. Spinal glial glutamate transporters downregulate in rats with taxol-induced hyperalgesia. Neurosci Lett 2005;386:18-22. [PubMed: 15975716]

Wiernik PH, Schwartz EL, Strauman JJ, Dutcher JP, Lipton RB, Paietta E. Phase I clinical and pharmacokinetic study of taxol. Cancer Res 1987;47:2486-93. [PubMed: 2882837] 
A

Figure 1.
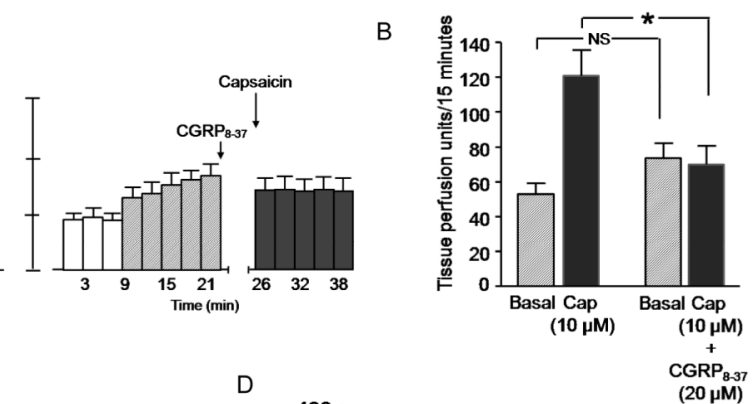

C

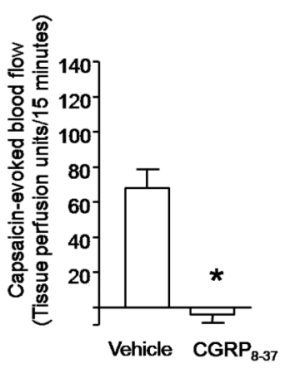

D

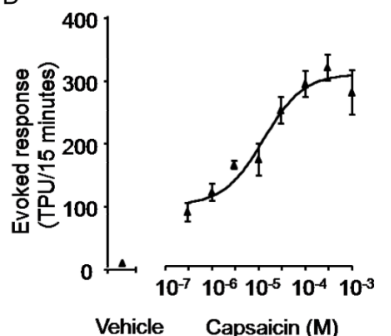

Capsaicin-induced vasodilatation in the hindpaw of the rat is blocked by the CGRP receptor antagonist $\mathrm{CGRP}_{8-37}$. In all cases, each column represents the mean $\pm \mathrm{SEM}$. A: The open columns and the hatched columns represent basal blood flow before and after the injection needle is inserted intradermally. The shaded columns represent blood flow after injection of vehicle then $10 \mu \mathrm{M}$ capsaicin (left panel) or $20 \mu \mathrm{M} \mathrm{CGRP}_{8-37}$ then capsaicin (right panel). $\mathrm{B}$ : Blood flow in tissue perfusion units over the $15 \mathrm{~min}$ prior to injection of vehicle or $\mathrm{CGRP}_{8-37}$ (hatched columns) and the $15 \mathrm{~min}$ after injection of capsaicin (shaded columns) from figure A. C: Capsaicin-evoked changes in blood flow over 15 minutes (capsaicinstimulated blood flow minus basal blood flow from figure $\mathrm{B}$ ) in vehicle- or $\mathrm{CGRP}_{8-37}-$ treated rats. In $\mathrm{B}$ and $\mathrm{C}$, an asterisk indicates statistical significance between the $\mathrm{CGRP}_{8-37}$ injected group and the vehicle-injected group. D: Each point is the mean \pm SEM evoked blood flow in TPU/15 min for vehicle or various concentrations of capsaicin injected into the hindpaws of 3-4 rats. 


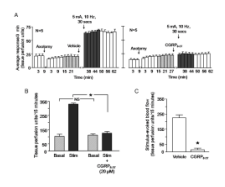

Figure 2.

Electrical stimulation of the rat sciatic nerve induces an increase in blood flow that is prevented by the CGRP receptor antagonist $\mathrm{CGRP}_{8-37}$. In all cases, each column represents the mean \pm SEM. A: The open columns and the hatched columns represent basal blood flow before and after the injection needle is inserted intradermally, whereas the shaded columns represent blood flow after electrical stimulation of the sciatic nerve after injection of vehicle

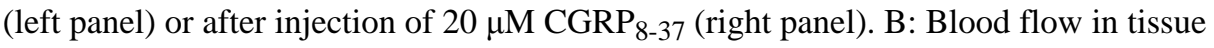
perfusion units over the $15 \mathrm{~min}$ prior to injection of vehicle or $\mathrm{CGRP}_{8-37}$ (hatched columns) and the 15 min after electrical stimulation (shaded columns) from figure A. C: Stimulationevoked release (stimulated release minus basal release in figure $\mathrm{B}$ ) in vehicle or $\mathrm{CGRP}_{8-37}$ treated rats. An asterisk in figures $\mathrm{B}$ and $\mathrm{C}$ indicates statistical significance between the $\mathrm{CGRP}_{8-37}$-injected group and the vehicle-injected group. 

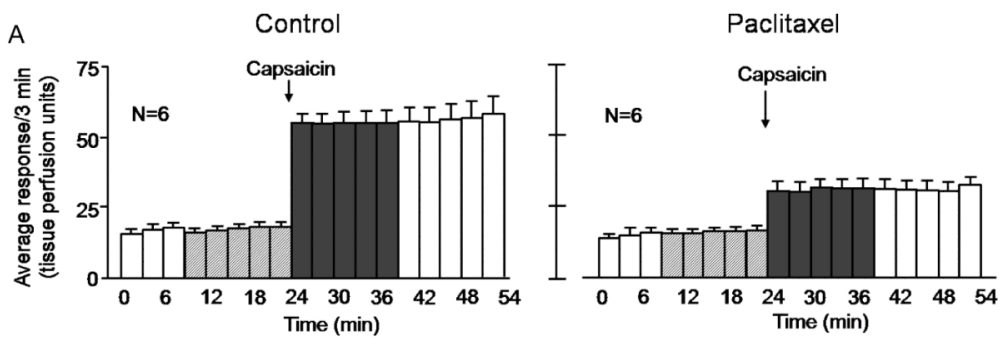

B

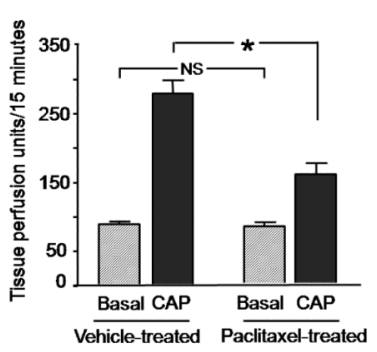

C

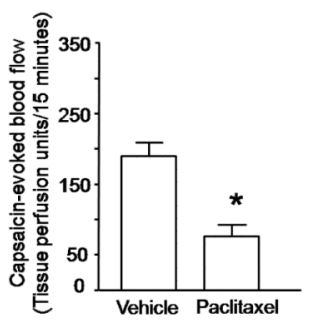

Figure 3.

Chronic administration of paclitaxel decreases capsaicin-induced vasodilatation in the rat hindpaw. In all cases, each column represents the mean \pm SEM. A: The open columns and the hatched columns represent basal blood flow before and after the injection needle is inserted intradermally. The shaded columns represent blood flow after injection of $10 \mu \mathrm{M}$ capsaicin in rats chronically administered vehicle (left panel) or animals chronically administered paclitaxel (right panel). B: Blood flow in tissue perfusion units over the $15 \mathrm{~min}$ prior to injection of capsaicin (hatched columns) and the 15 min after injection of capsaicin (shaded columns) in vehicle-treated or paclitaxel-treated animals from figure A. C:

Capsaicin-evoked changes in blood flow over 15 minutes (capsaicin-stimulated blood flow minus basal blood flow from figure B) in vehicle- or paclitaxel-injected animals. In B and C, an asterisk indicates statistical significance between the paclitaxel treated group and the vehicle-injected group. 

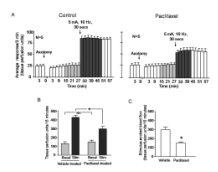

Figure 4.

Chronic administration of paclitaxel decreases electrical stimulation-induced vasodilatation in the rat hindpaw. In all cases, each column represents the mean \pm SEM. A: The open columns represent the basal blood flow before or after axotomy as indicated. The hatched columns show the blood flow after the injection needle is inserted intradermally, whereas the shaded columns represent blood flow after electrical stimulation of the sciatic nerve in rats that were administered vehicle (left panel) or paclitaxel (right panel). B: Blood flow in tissue perfusion units over the $15 \mathrm{~min}$ prior to electrical stimulation (hatched columns) and the 15 min after electrical stimulation (shaded columns) in vehicle-treated or paclitaxeltreated animals from figure A. C: Stimulation-evoked release (stimulated release minus basal release in figure B) in vehicle- or paclitaxel-injected animals. In B and C, an asterisk indicates statistical significance between the paclitaxel treated group and the vehicleinjected group. 


\section{II \\ H II}

Figure 5.

Chronic administration of paclitaxel does not alter CGRP-induced or methacholine-induced vasodilatation in the rat hindpaw. In all cases, each column represents the mean \pm SEM. A and $\mathrm{C}$ : The open columns and the hatched columns represent basal blood flow before and after the injection needle is inserted intradermally. The shaded columns represent blood flow after injection of $30 \mu \mathrm{M}$ CGRP (A) or $100 \mu \mathrm{M}$ methacholine (C) in rats administered vehicle (left panel) or animals administered paclitaxel (right panel). B: Blood flow in tissue perfusion units over the 15 min prior to injection of CGRP (hatched columns) and the 15 min after injection of CGRP (shaded columns) in vehicle-treated or paclitaxel-treated animals from figure A. D: Blood flow in tissue perfusion units over the 15 min prior to injection of methacholine (hatched columns) and the $15 \mathrm{~min}$ after injection of methacholine (shaded columns) in vehicle-treated or paclitaxel-treated animals from figure C. 

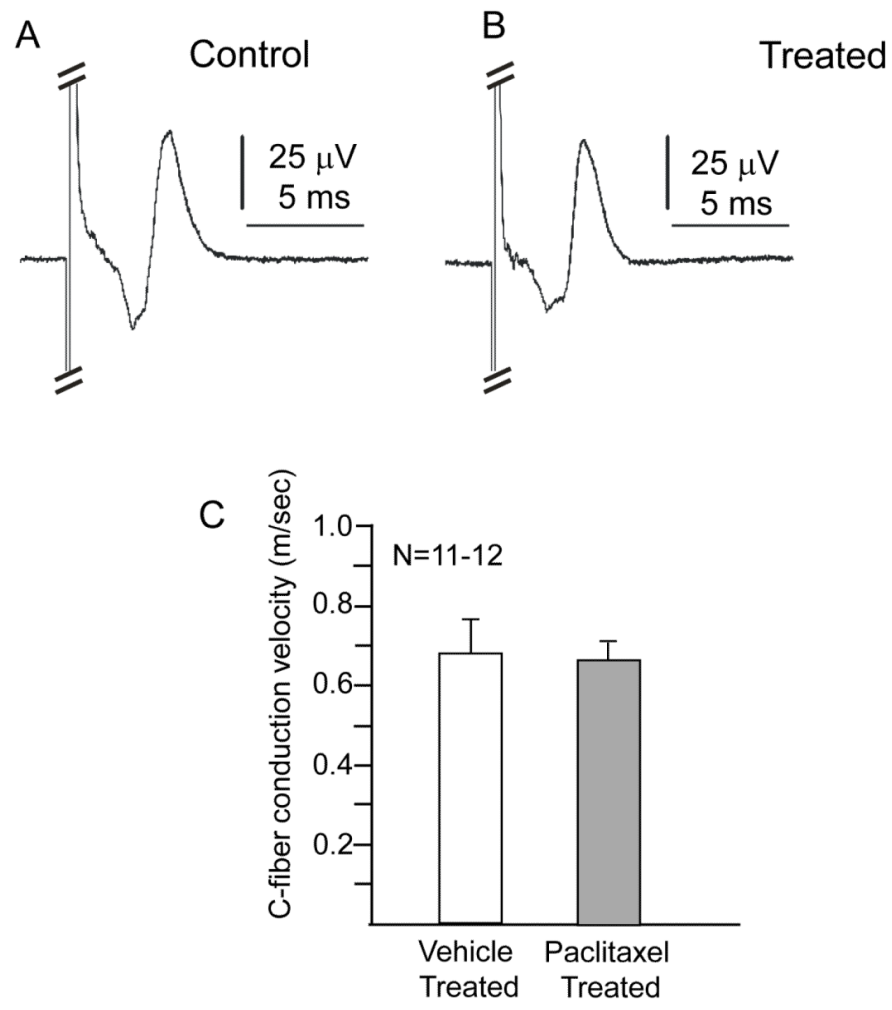

Figure 6.

Paclitaxel treatment does not alter C-fiber action potentials or conduction velocity. The top panels show representative $\mathrm{C}$-fiber compound action potentials (CAPs) recorded from sciatic nerves isolated from vehicle-treated (A) and paclitaxel-treated (B) rats. Compound action potentials were stimulated with $5 \mathrm{~mA}$ current pulses of $1 \mathrm{~ms}$ duration. The A-fiber response, which is hidden in part by the stimulus artifact, is cropped in order to focus on the $\mathrm{C}$-wave. The bottom panel shows the mean $\pm \mathrm{SEM}$ of the $\mathrm{C}$-fiber conduction velocities in $\mathrm{m} / \mathrm{sec}$ for vehicle treated (open column) and paclitaxel treated (shaded column) rats. 
A

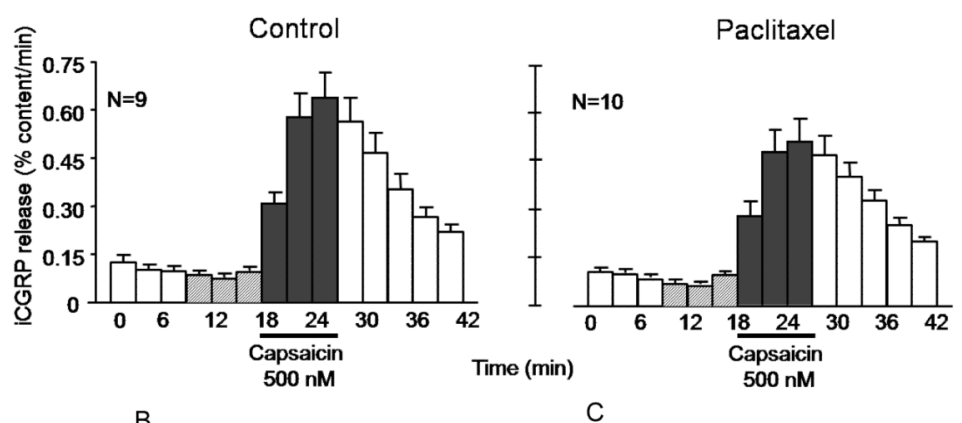

B
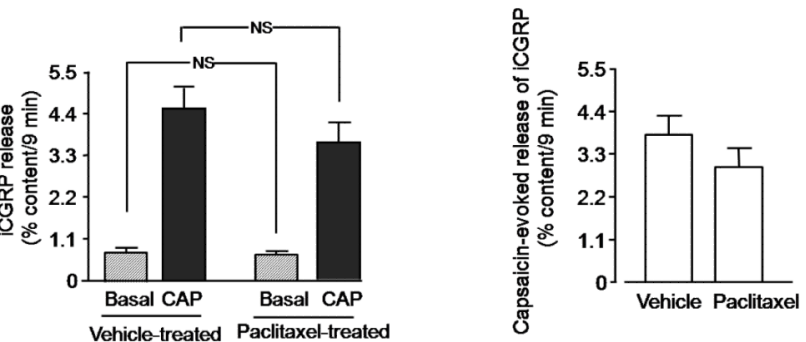

Figure 7.

Chronic administration of paclitaxel does not decrease capsaicin-evoked iCGRP release from rat spinal cord slices. In all cases, each column represents the mean \pm SEM. A: iCGRP release in each 3-minute perfusion sample expressed as percent of total peptide content per minute. The horizontal bar indicates the time when the tissues were exposed to $500 \mathrm{nM}$ capsaicin. The left panel represents release in slices taken from vehicle-treated rats, whereas the right panel is from rats chronically administered paclitaxel. B: Release of iCGRP over 9 minutes in vehicle-treated or paclitaxel-treated rats as indicated. Basal release is the sum of the 3 collections prior to capsaicin, whereas capsaicin-stimulated release is the sum of the three collections in the presence of capsaicin from figure A. C: Evoked release of iCGRP (capsaicin-stimulated release minus basal release presented in figure B) in vehicle- or paclitaxel-treated rats, as indicated. 